\title{
Avaliação da Qualidade Microbiológica e Sensorial de Abacaxi (Smooth Cayenne) Minimamente Processado, Revestidos com Diferentes Gomas
}

Sandriane Pizato (li), Janaina Mayumi Honma (I), Gisele Fernanda Alves Da Silva (I), Marcela Felix Dos Santos (I), Tailine Saturnino Da Costa (I), William Renzo Cortez Vega (I)

(I) UFGD - UNIVERSIDADE FEDERAL DA GRANDE DOURADOS (R. João Rosa Góes, 1761, Vila Progresso, Dourados - MS, 79825-070), (II) FURG - UNIVERSIDADE FEDERAL DO RIO GRANDE (Av. Itália km 8 Bairro Carreiros)

\section{Resumo}

A injúria nos tecidos, em função do processamento mínimo, pode diminuir a qualidade e o tempo de vida útil das frutas. Uma alternativa para reduzir os efeitos causados pelo processo mínimo é o uso de gomas comestíveis. O objetivo do presente trabalho foi avaliar o uso de três diferentes gomas como revestimentos comestíveis para a manutenção da qualidade microbiológica e sensorial de abacaxis minimamente processados, armazenados a $4 \pm 1^{\circ} \mathrm{C}$ durante 12 dias. Os abacaxis (Smooth cayenne) foram lavados, descascados e cortados em cubos. Estes foram mergulhados em água clorada. As gomas foram preparadas e após o resfriamento das soluções foram adicionados o cloreto de cálcio, os ácidos cítrico e ascórbico e o plastificante glicerol. Os pedaços foram totalmente submersos nas soluções por 1 minuto e drenados para que o excesso de solução fosse eliminado. Estes foram armazenados em embalagem PET, por um período de 12 dias a $4 \pm 1^{\circ} \mathrm{C}$. Obteve-se 4 tratamentos: T1 Controle (abacaxi cortado); T2 - goma pectina; T3 - goma tara; T4 - goma xantana. Foram realizadas análises microbiológicas (psicrotróficos, bolores e leveduras, Salmonella e Escherichia coli). Para a análise sensorial foram utilizados 12 julgadores previamente treinados. Os atributos avaliados foram textura, cor, aroma e avaliação global. A escala utilizada foi de 5

\footnotetext{
Referência:

Sandriane Pizato, Janaina Mayumi Honma, Gisele Fernanda Alves Da Silva, Marcela Felix Dos Santos, Tailine Saturnino Da Costa, William Renzo Cortez Vega . Avaliação da Qualidade Microbiológica e Sensorial de Abacaxi (Smooth Cayenne) Minimamente Processado, Revestidos com Diferentes Gomas. In: Anais do 12 Congresso Latinoamericano de Microbiologia e Higiene de Alimentos - MICROAL 2014 [= Blucher Food Science Proceedings, num.1, vol.1]. São Paulo: Editora Blucher, 2014. DOI 10.5151/foodsci-microal-125
} 
(aceitável para consumo) a 1 (inaceitável para consumo), sendo considerado o limite de aceitabilidade o valor 3 . As análises foram realizadas em triplicata em $0,1,3,5,7,9$ e 12 dias de armazenamento. Não foi detectada a presença de Salmonella spp e Escherichia coli

Palavras-Chave: Coberturas, Microbiologia , Abacaxi, sensorial Agência de Fomento: 